\title{
3
}

\section{Growth accounting after statistical revisions}

\section{Xiaolu Wang}

This chapter examines the size, per capita level, structural characteristics and growth rate of the Chinese economy after the new statistical revisions recently released, as a result of the countrywide economic census at the end of 2004 and other surveys in 2005 and 2006. New growth accounting analyses are carried out to assess the contribution of factors and productivity to China's economic growth. The greater size of the economy indicated by the new statistics has new implications for the driving forces of growth.

The first section of the chapter reviews the revisions of GDP statistics and looks at the economic implications of the size and per capita levels of the Chinese economy, and discusses issues relating to the economic growth rate. The second section discusses the structural characteristics of the Chinese economy indicated by the revised statistical data, and the implications for future growth. The third section carries out a growth accounting analysis to examine the contribution of factors and productivity changes to economic growth, and is followed by a conclusion.

\section{How large is the Chinese economy after statistical revisions?}

China carried out a new economic census on 31 December 2004, covering all economic activities in secondary and tertiary industries. The census indicated that the size of the Chinese economy was seriously understated in previous statistics, due mainly to incomplete statistical systems for the services sector, indicating that values were missing from small enterprises in that sector. Total 
GDP data for 2004 and earlier years up to 1978 were revised and published by the National Bureau of Statistics in 2006 (National Bureau of Statistics 2006a), however, major revisions have been made to the data since the early 1990s (a nationwide census for tertiary industries was carried out in 1993). According to the new statistical revisions, the Chinese economy in 2004 was 16.8 percentage points larger than previously reported. At the provincial and sectoral levels, some revised data for 2004 are also available in the China Statistical Monthly (National Bureau of Statistics 2006b), and allow comparisons between the revised and unrevised data (see National Bureau of Statistics 2005c) in different dimensions.

A comparison between the revised and unrevised GDP data (1991-2005, current prices) is shown in Figure 3.1. Figure 3.2 shows the official revisions of the GDP growth rates for the same period.

According to the new statistics, the average economic growth rate for the period 1993-2004 was 9.9 per cent, rather than the previously announced figure of 9.4 per cent. The growth rate remained the same into 2005, while in the first six months of 2006, GDP growth reached 10.9 per cent (Zheng 2006).

In 2005, China's total GDP was 18,232 billion yuan, or US $\$ 2,229$ billion (World Bank 2006). In terms of economic size, China's economy surpassed the United Kingdom and France in 2005 and is now ranked fourth in the world. According to the World Bank's Purchasing Power Parity (PPP) measure, China's GDP was US $\$ 8,573$ billion in 2005; that is, 3.85 times as large as stated above, and more than twice that of Japan. The PPP measure ranks China in second place globally, after the United States (World Bank 2006).

In terms of per capita GDP, China is still a poor country, although not as poor as previously stated. In 2005, GDP per capita in China was RMB13,944 or US\$1,704. According to the World Bank's PPP measure (based on Ren and Chen's study, 1995) China's GDP per capita was US $\$ 6,556$, making it already a middle-income country.

There have been some concerns about a possible upward bias of the World Bank's estimations because the differences in quality between products in China and industrial countries have been ignored. There are other studies that derived similar or different results to the World Bank's estimations. Garnaut and Ma (1993) and Garnaut and Huang (1994) compared consumption of food, steel, energy and other goods in China and other economies and concluded that the real GDP of China should be adjusted by a factor of three. Wu (1997) reviewed different PPP estimates and suggested China's GDP was three times higher than the marketexchange rate converted level. Wu also pointed out that the PPP measure indicated only the Chinese people's standard of living, and should not be interpreted as 
Figure 3.1 China's GDP, revised and unrevised, 1991-2005 (trillion yuan)

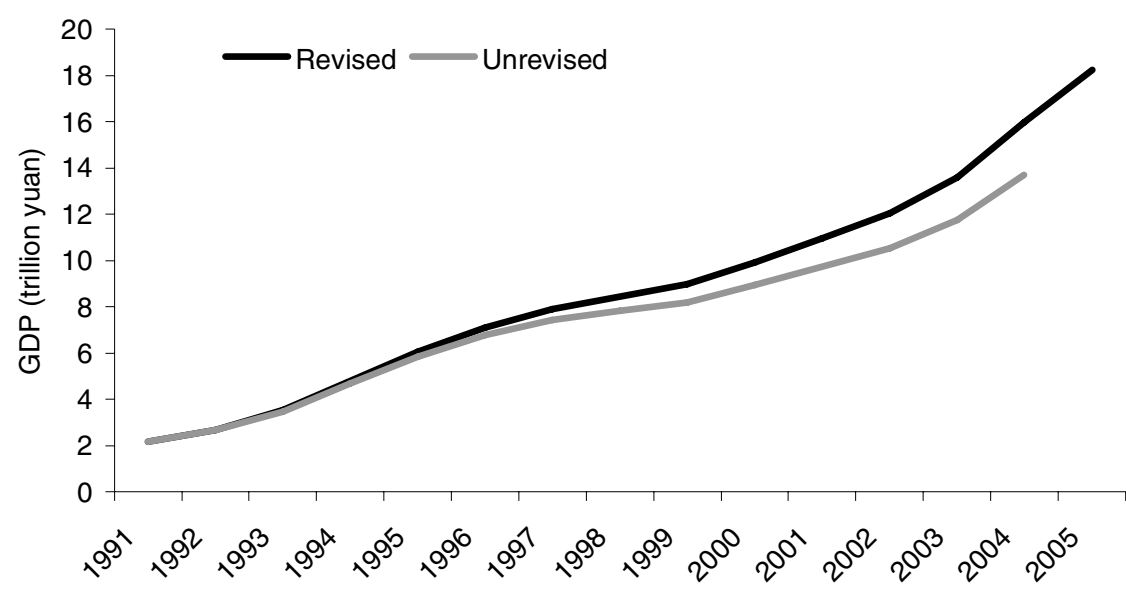

Sources: National Bureau of Statistics of China, 2006a. China Statistical Abstract 2006, China Statistics Press, Beijing. National Bureau of Statistics of China, 2005c. China Statistical Yearbook, China Statistics Press, Beijing.

Figure 3.2 GDP growth rate, revised and unrevised, 1991-2005 (per cent)

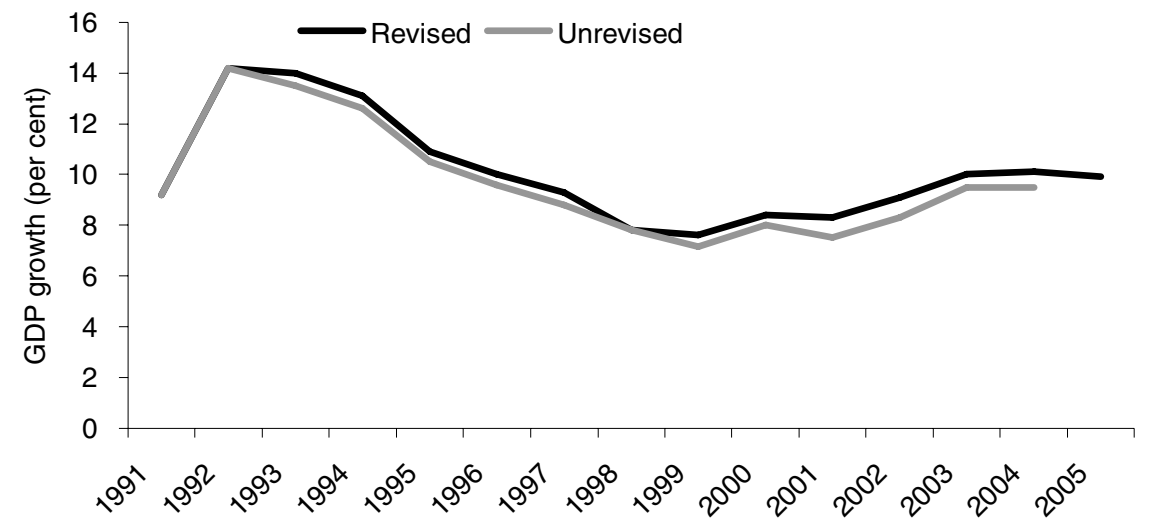

Sources: National Bureau of Statistics of China, 2006a. China Statistical Abstract 2006, China Statistics Press, Beijing. National Bureau of Statistics of China, 2005c. China Statistical Yearbook, China Statistics Press, Beijing. 
representing China's economic power in the world market. Other estimates of China's PPP measure include Maddison (1998) and Heston et al. (2002). In a late estimation, Heston et al. (2002) estimated that China's GDP per capita (PPP) in the year 2000 was US $\$ 3,843$. This was about 4.5 times greater than the figure derived from the 2000 exchange rate using unrevised statistical data.

It should also be taken into account that many studies were carried out some time ago and relative domestic prices between China and other countries have since changed, especially with China's process of internationalisation, this, therefore, might reduce the factor for China's GDP conversion. If we take a possible range of 3.0 to 3.8 for a reasonable conversion factor, then GDP per capita in China in 2005 might have been in the range of US $\$ 5,000-6,500$, and its total GDP in the range of US $\$ 6,600-8,600$ billion. In any case, China's GDP in PPP measures is larger than that of Japan (US $\$ 3,943$ billion) but significantly smaller than the United States (\$12,409 billion).

The statistical revisions have also changed the relative position of different regions in terms of economic development. In Figure 3.3, all 31 provinces (including five autonomous ethnic regions and four municipalities administrated at the provincial level) are ranked by their economic size according to the revised data. Of the top 11 provinces, nine are in the east coast areas, whereas, of the bottom 10 provinces, nine are in the west. The middle 10 provinces are located mainly in the central and northeast areas.

Figure 3.3 shows how much the data were revised upwards or downwards for each province. GDP was adjusted upwards by 41 per cent for Beijing and by more than 10 per cent for several provinces including Guangdong, the largest province in terms of economic size, and Ningxia, a less developed autonomous region in western China. Downward adjustments were made to 11 of the 31 provinces. Of those, Heilongjiang and Hubei, two provinces at the middle level in economic development, each lost more than 10 per cent. In general, the more advanced east coast region and the underdeveloped western region gained, respectively, by 4.4 and 3.8 per cent, while the central region, which was at the middle level of economic development, lost 2.1 per cent of its GDP.

Such figures might puzzle many readers, since GDP was revised upwards by 16.8 per cent in 2004, but the aggregate of provincial GDP was increased by only 2.7 per cent. This is because, for a long period, the National Bureau of Statistics believed that GDP at the provincial level was overstated, therefore they made their own adjustment to the national GDP according to various economic surveys, without adjusting the provincial data. For example, the National Bureau of Statistics had announced that the unrevised 2004 GDP was RMB13,687 billion, whereas 
Figure 3.3 Adjustment of GDP data at the provincial level, 2004 (billion yuan)

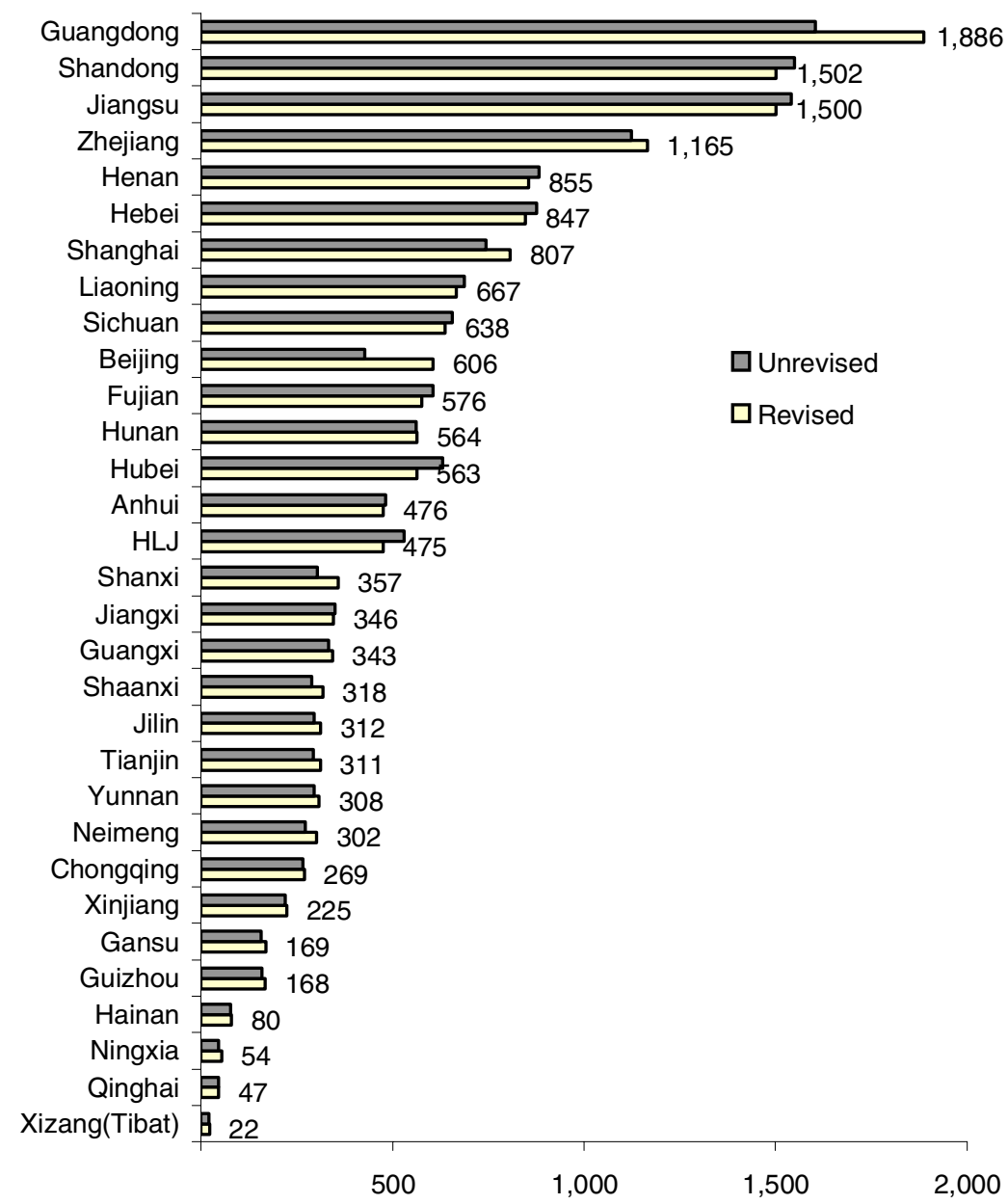

Note: Data in the chart are revised figures. Unrevised data are not shown due to space limitations.

Sources: National Bureau of Statistics of China, 2006a. China Statistical Abstract 2006, China Statistics Press, Beijing. National Bureau of Statistics of China, 2005c. China Statistical Yearbook, China Statistics Press, Beijing. 
the provincial sum was RMB16,324 billion. The latter is 19 per cent greater than the former. After the new statistical revision, the two figures are closer, although still inconsistent. The revised GDP in 2004 was RMB15,988 billion for the national total and RMB16,760 billion for the provincial sum. The latter is still 5 per cent greater. In 2005, the announced total GDP and the published provincial sum of GDP were RMB18,232 billion and RMB19,657 billion, respectively. The latter is 7.8 per cent greater than the former.

Was the unrevised GDP data at the provincial level more reliable? The answer is no. First, data for individual provinces changed largely after the economic census. Only in the aggregate was the total change small, because the upward and downward changes offset one another. Second, while the previous data for tertiary industries in most provinces were found to be understated, data for secondary industries were overstated in a number of provinces. This was the reason for the National Bureau of Statistic's previous downward adjustments. ${ }^{1}$ Comparing the new 2005 data for GDP structure at the provincial level with the unrevised data in 2004 (revised 2004 data are not available at this stage), one finds that the size of secondary industries in current prices shrank by 6 to 7 per cent in Heilongjiang and Hubei, although both claimed GDP growth of more than 11 per cent (data from National Bureau of Statistics 2006a, 2005c). In a few other provinces, the changes for secondary industries were too small to be consistent with their economic growth rates, indicating that the previous data on secondary industries were over-reported.

In terms of growth statistics, there is still a large gap between the growth rates of the national GDP and the provincial average. In 2005, based on the new statistical data announced by the National Bureau of Statistics, the GDP growth rate was 9.9 per cent, whereas the weighted provincial average was 12.9 per cent-three percentage points higher than the former. This inconsistency still exists.

It is too early to judge whether some local governments still intend to overstate their economic performance after the national economic census. There are, however, some other likely reasons for the lower growth rates stated by the National Bureau of Statistics at the national level. One is how the data are deflated. The author constructed an alternative GDP deflator to compare with the implicit GDP deflator used by the National Bureau of Statistics. Four price indexes are used. They are Consumer Price Index (CPI), ex-factory Price Index of Industrial Products (PIIP), Producer Price Index of Farm Products (PPIF; Purchasing Price Index of Farm Products is used for the period before 2001) and Fixed Investment Price Index (FIPI). These are the major price indexes provided by the National Bureau of Statistics, and cover the main (although not all) areas of economic activity. 
Price indexes at the national and provincial levels are calculated separately. Different weights for the four indices are taken for sensitivity tests, and the results are very close. $^{2}$

Interestingly, comparisons between the National Bureau of Statistics' deflator and the alternative deflator show significant differences. For the period from 1996 to 2005 , the National Bureau of Statistics' price index was generally higher than the alternative index by an average of 1.2 percentage points. For the earlier period, from 1978 to 1995 , however, it was generally lower than the latter by an average of 0.9 percentage points.

The alternative deflators at the national level and for each province are used to derive the national and provincial GDP growth rates to compare with the official growth rates. Revised and unrevised GDP data in current prices for the period from 1992 to 2005 are used. The results are shown in Table 3.1 and they indicate significant inconsistency between the official growth rates at the national level and those at the provincial level-the latter is 2.4 percentage points higher than the former (unrevised data). The alternative deflator gives more consistent growth rates between the national total and provincial aggregate. For unrevised GDP data, there is a 1.4 percentage point difference between them and, for revised data, the gap was further reduced to 0.3 percentage points.

Table 3.1 shows an alternative growth rate that is higher than the official rate, based on the revised GDP data. The alternative states a growth rate of 10.7 per cent for the 1992-2004, 0.5 percentage points higher than the official rate. In contrast, when unrevised data are used, the alternative rate is lower than the official one. Therefore there are greater changes in growth rates after the data

\section{Table 3.1 Average GDP growth rate in 1992-2004 by different sources}

\begin{tabular}{lccc}
\hline & National total & Provincial sum & Inconsistency \\
Official (unrevised) & 9.7 & $12.1^{\mathrm{a}}$ & 2.4 \\
Official (revised) & 10.2 & n.a. & n.a. \\
Alternative (unrevised) ${ }^{\mathrm{b}}$ & 9.4 & $10.8^{\mathrm{c}}$ & 1.4 \\
Alternative (revised) $^{\mathrm{b}}$ & 10.7 & $11.0^{\mathrm{c}}$ & 0.3 \\
\hline
\end{tabular}

Notes: ${ }^{a}$ Weighted average using the shares of provincial GDP in aggregate as the weights. ${ }^{b}$ Calculated by the author using GDP in current prices and the alternative deflator. ${ }^{\circ}$ Calculated by the author from the deflated sum of provincial GDP using the alternative deflators at the provincial level.

Sources: National Bureau of Statistics of China, 2006a. China Statistical Abstract 2006, China Statistics Press, Beijing. National Bureau of Statistics of China, 2005c. China Statistical Yearbook, China Statistics Press, Beijing. 
revision. In the official statistics, the average growth rate in the 1992-2004 period was revised upwards from 9.7 per cent to 10.2 per cent, an increase of 0.5 percentage points. By the alternative calculation, however, the average growth rate should be revised from 9.4 per cent to 10.7 per cent, an increase of 1.3 percentage points.

Again, the growth rate change in the alternative calculation is more consistent with the findings from the economic census. According to the outcome of the census, the economy in 2004 was 16.8 per cent larger than reported earlier, whereas a 0.5 percentage point upward revision of the growth rate from 1992 to 2004 makes the total GDP only 6 per cent larger. Using the alternative growth rates, one can find that the total GDP was 16 per cent larger after the data revision.

Is the alternative GDP growth rate for China suggested in this chapter reliable? This might need further confirmation in future studies. Nevertheless, for the first half of 2006, the National Bureau of Statistics reported a further speed up of GDP growth, at a rate of 10.9 per cent. A high growth rate of more than 10 per cent might be expected for the near future.

\section{The structure of the Chinese economy}

Major changes occurred to the size of the services sector after the statistical revision. Table 3.2 shows minor increases in value-adding in primary and secondary industries after the revision (by 0.7 per cent and 2 per cent, respectively), but a major increase in tertiary industries (by 49 per cent). The previous data showed an unbalanced structure in the Chinese economy, with an obviously low proportion of the services sector and a high proportion of the industrial sector in GDP, compared with most other economies with either the same or higher levels of development. After the data revision, the share of tertiary industries in GDP is now closer to the common pattern, although it is still low. It increased from 32 per cent to 41 per cent. Meanwhile, the share of the secondary sector decreased from 53 per cent to 46 per cent in 2004 (Figure 3.4).

Another abnormality of the GDP structure was the very low proportion of private consumption and very high ratio of capital formation. The statistical revision did not make any positive change to this picture, rather, the share of private consumption in GDP in 2004 dropped by 1.6 percentage points, from 41.4 per cent to 39.8 per cent. Government consumption increased by three percentage points, and capital formation decreased by one point (Figure 3.5). Private consumption dropped further, by 1.6 percentage points, to 38.2 per cent in 2005, which was the lowest in at least the past half a century. 
Table 3.2 Changes in GDP structure, 2004 (billion yuan)

\begin{tabular}{lccc}
\hline & 2004 unrevised & 2004 revised & Change (per cent) \\
Primary & 2,081 & 2,094 & 0.7 \\
Secondary & 7,241 & 7,386 & 2.0 \\
Tertiary & 4,366 & 6,507 & 49.0 \\
\hline
\end{tabular}

Sources: National Bureau of Statistics of China, 2006a. China Statistical Abstract 2006, China Statistics Press, Beijing. National Bureau of Statistics of China, 2005c. China Statistical Yearbook, China Statistics Press, Beijing.

Figure 3.4 GDP structure after the statistical revisions, 2004 and 2005 (per cent of GDP)

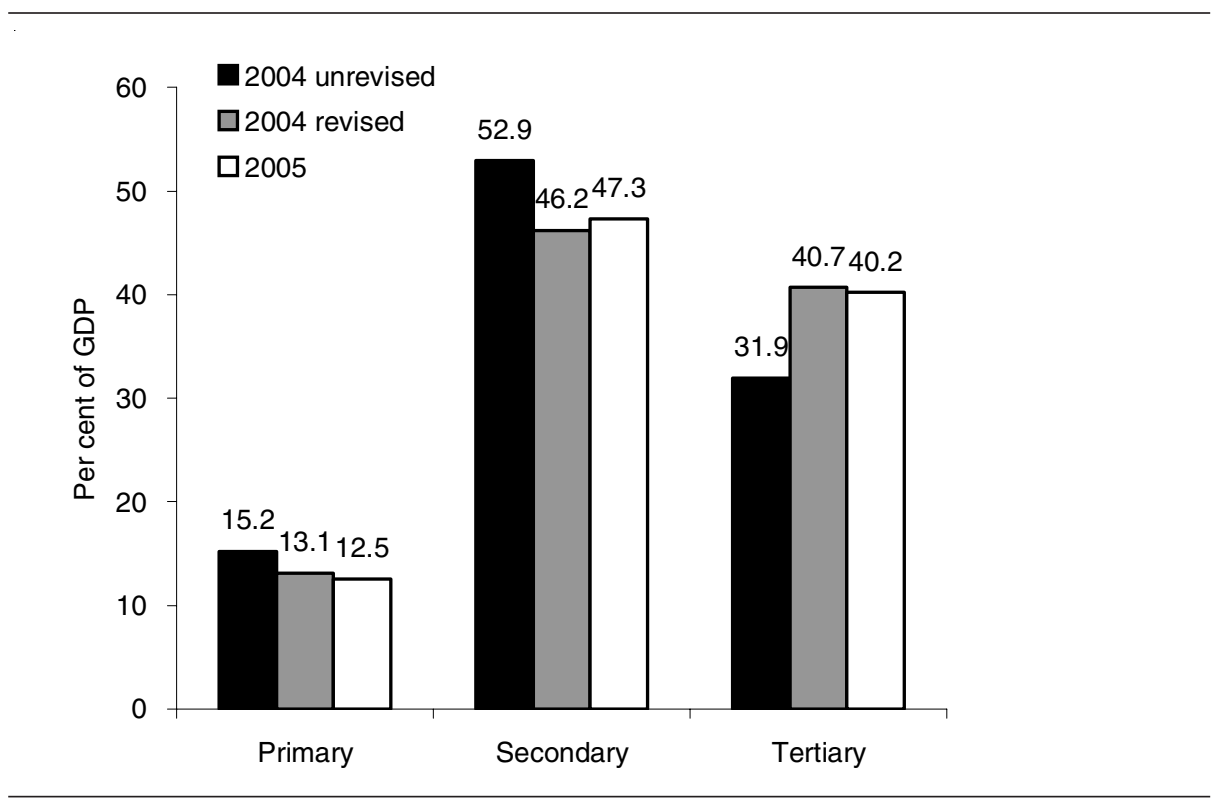

Sources: National Bureau of Statistics of China, 2006a. China Statistical Abstract 2006, China Statistics Press, Beijing. National Bureau of Statistics of China, 2005c. China Statistical Yearbook, China Statistics Press, Beijing. 
Figure 3.5 GDP components by expenditure, 2004 (per cent)

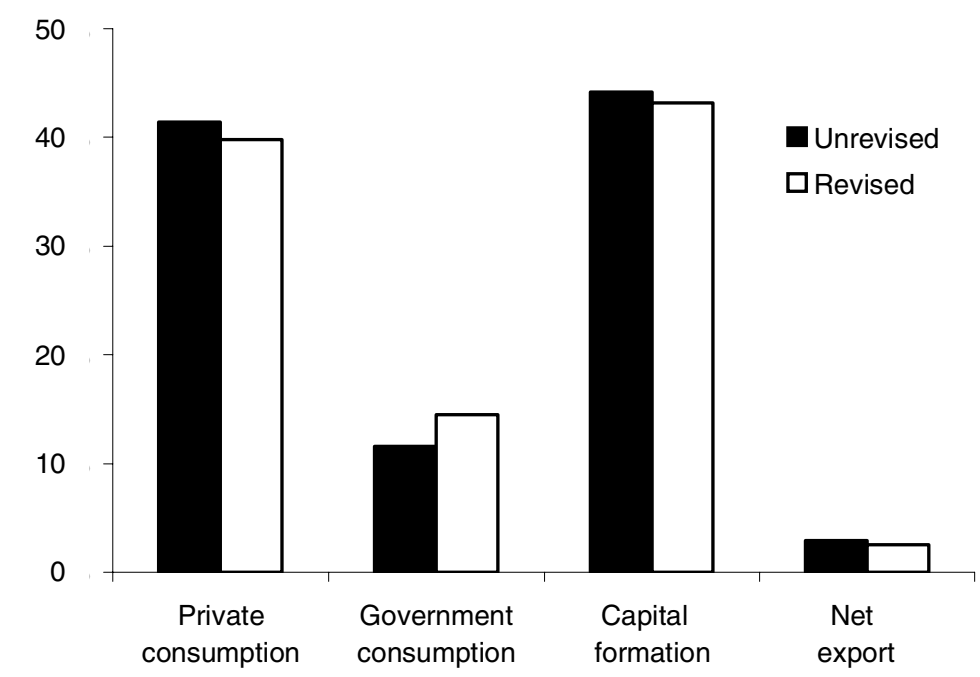

Sources: National Bureau of Statistics of China, 2006a. China Statistical Abstract 2006, China Statistics Press, Beijing. National Bureau of Statistics of China, 2005c. China Statistical Yearbook, China Statistics Press, Beijing.

The relatively weak consumption growth resulted in deficiency in aggregate demand, pushing up net exports and fuelling high investment. While strong investment lifts up aggregate demand in the short run, it also creates rapid growth of production capacity in the longer term. With slower consumption growth, overcapacity appears later in some industrial sectors, and further generates upward pressure on net export and downward pressure on prices. While economic growth rate remained high, CPI decreased from 3.9 per cent in 2004 to 1.7 per cent in 2005 , and then to 1.5 per cent in the first half of 2006. Meanwhile, the share of net export in GDP increased from 2.5 per cent in 2004 to 4.5 per cent in 2005 when renmimbi moderately appreciated in the middle of the year. The export pressure has resulted in more trade disputes.

Insufficient consumption demand also leads to inefficient use of resources. In 1999, total amount deposited in banks and other financial institutions were 10,878 billion (1.2 times GDP), and the loan-deposit ratio was 86.2 per cent. In 2005, the total amount deposited grew to 28,717 billion (nearly 1.6 times GDP), and the 
loan-deposit ratio dropped to 67.8 per cent. Although total loans increased at a real annual rate around $10-11$ per cent (by different deflators), a greater proportion of bank deposits became unused.

Foreign exchange reserves also mounted. According to the State Administration of Foreign Exchange, reserves achieved an historical high of US\$ 941 billion at the end of June 2006, - - the highest amount worldwide. A large part has been invested in US treasury bonds. Whether China needs this amount of reserves and whether this is an efficient use of foreign exchange is now a controversial issue.

Private consumption is depressed by a few factors: employment uncertainty, incomplete social security systems, the high prices of social services (mainly medical services and higher education) and real estate. The rapid increase in income disparity is also responsible (Wang 2005). In the past 20 years, the Gini coefficient increased from 0.27 (in 1985) to 0.45 (in 2004). While incomes for high income earners increased rapidly, those of low-income earners changed slowly, or even decreased. This had a negative impact on private consumption because rich people are able to save far more than poor people. In addition, the incomplete taxation system taxes poor people more than the rich, because the latter have much greater chances for tax evasion.

All of the above indicate necessities for improvement in the social security system, public services and the taxation system. For the sustainability of long-term economic growth, institutional reform for a better-managed public service sector, with more efficiency, more transparency and more public monitoring, is essential.

\section{Growth accounting after statistical revision}

China has managed to maintain a very high economic growth rate during the past 28 years, since the beginning of its economic reform in the official data, at an average of 9.7 per cent. This growth was, however, criticised by some researchers as being unsustainable, and as being driven mainly by heavy investment or input growth (for example, Krugman 1994; Young 2000). Meanwhile, many other researchers found moderate productivity changes but the major source of growth was the increase in inputs. What is the overall picture after the statistical revisions? In this section, I attempt to provide a preliminary answer to this question via growth accounting analysis, based on the newly revised statistical data.

Considering the continued increases in the education levels of the labour force in China, and the new phenomenon of labour-supply shortage, human capital is expected to play a more important role in China's economic growth. For this reason, a Lucas-style growth model (Lucas 1988) is used for growth accounting 
The Turning Point in China's Economic Development

$Y_{t}=A_{0} K_{t}^{a} H_{t}^{(1-a)} H_{a(t)}{ }^{b} X_{1 t}{ }^{g 1} X_{2 t}{ }^{22} \ldots X_{n t}{ }^{g n}$

where $Y_{t}$ is real GDP of the year ' $t$ '; $K_{t}$ is capital stock; $H_{t}$ is education-enhanced labour force, or stock of human capital; $\mathrm{H}_{\mathrm{a}}$ is the average education level of the labour force; $X_{\text {it }}$ represents other variables that might effect total factor productivity growth; a and 1-a are, respectively, the elasticities of capital and human capital with respect to GDP under the restriction of constant returns to scale; b catches the possible externality of average education on growth, as a source of TFP changes; $g_{i}$ represents the effect of the 'ith' factor on TFP growth; and $A_{0}$ is a constant that presents the initial level of TFP.

The model is estimated empirically in a logarithm form, with and without the restriction on constant returns to scale. To impose the restriction, the model is transformed as follows

$\ln \mathrm{y}_{\mathrm{t}}=\mathrm{C}+\mathrm{alnk}_{\mathrm{t}}+\mathrm{blnH}_{\mathrm{a(t)}}+\Sigma\left(\mathrm{g}_{\mathrm{i}} \ln \mathrm{X}_{\mathrm{it}}\right)$

where $\mathrm{y}_{t}=\mathrm{Y} / \mathrm{H}_{t}, \mathrm{k}_{t}=\mathrm{K} / \mathrm{H}_{t}$, and $\mathrm{i}=\mathrm{i}(1,2, \ldots \mathrm{n})$.

National-level data for the 54-year period from 1952 to 2005 are used (National Bureau of Statistics 2005c, 2005d, 2006a). Two sets of GDP data-that is, revised and unrevised - are used and deflated to 1978 prices using the implicit National Bureau of Statistics GDP deflator. Capital stock is calculated based on historical data of total investment in fixed assets and the price index for fixed investment, using the Perpetual Inventory Method. To avoid shortage of data on various categories of capital stock, an overall depreciation rate of 5 per cent is used. For the initial capital stock in 1952, the author took RMB70 billion, based mainly on Chow (1993). ${ }^{3}$

Human capital $\left(\mathrm{H}_{t}\right)$ is defined as total labour force times years of schooling. The accumulation of $\mathrm{H}_{t}$ for each year from 1952 to 2005 is calculated from graduation and one education period of lagged enrolment data, from primary to postgraduate education. The calculation used the information from the 1964, 1982, 1990 and 2000 national population censuses. Incomplete school education (that is, the differences between graduation and period of lagged enrolment) is assumed to have an average length of 50 per cent of the corresponding education period. Vocational education, adult education, special education, overseas study and informal training programs are also calculated. Human capital depreciation is calculated based on the death rate of the population and the calculated average 
years of schooling of the population (not of the labour force) with a time lag. ${ }^{4}$ The initial human capital stock in 1952 was projected as an average of 1.3 years of schooling of the total population. This is based on 1964 national census data on education and detailed education data between 1952 and 1964.

A number of variables are tested for $X_{\mathrm{S}}$, that is, sources of TFP growth other than the externality of education. They are marketisation, urbanisation, foreign trade, foreign investment and research and development. Marketisation has been found to have a positive effect on factor allocation and possibly on technological innovation. Urbanisation can increase TFP as it transfers inefficiently used labour and other resources from rural to urban sectors, thus increasing efficiency. Foreign trade exploits comparative advantages in the economy, and might also lead to technological transfers. Foreign investment can bring new technology and management skills into the country. Research and development directly promotes technological innovation.

For marketisation in the period under investigation, the shares of non-state enterprises (that is, private enterprises, foreign-funded enterprises and shareholding companies) in the values of industrial output are used as a proxy (NSE). Urbanisation is defined as the ratio of urban to total population. Because its impact on TFP is mainly in the reallocation of resources-that is, a short-term effectthe changes in the urbanisation ratio $(\mathrm{Ud})$ were used in this study. To present the level of foreign trade (or economic openness), the sum of total export and import values as a ratio to GDP is used (TRY). For foreign investment, the ratio of Foreign Direct Investment (FDI) (converted at the official exchange rate) to total investment in fixed assets is used (FI). Data for overall research and development activities are not available; instead, government expenses on research and development as a proportion of GDP are used (GRY).

There are also some possible drags of TFP growth. In this context, one factor being considered commonly is inefficient use of government resources. In China, government expenses on administration and the operating costs of government departments accounted for a large proportion of total government expenditure. In this study, the ratio of these government expenses to GDP is used (GAY) to test the possible effect on TFP.

Normally, there are time lags between investment in and utilisation of industrial capital, and between the graduation of students and when they become skilled employees. For this reason, and to avoid possible bi-causal problems, one-year lagged variables of $\mathrm{K}, \mathrm{H}$, and $\mathrm{H}_{\mathrm{a}}$ are used in the equations. The Prais-Winsten regression method is used for auto-correlation. The results are reported in Table 3.3. 


\section{Table 3.3 Estimation result: Prais-Winsten Regression AR(1)}

\begin{tabular}{|c|c|c|c|c|c|}
\hline Dep. var & $\begin{array}{c}\ln _{\mathrm{t}} \\
\text { Equation } 1 \\
\text { (unrestricted) }\end{array}$ & $\begin{array}{c}\text { Iny }_{t} \\
\text { Equation 1' } \\
\text { (unrestricted) }\end{array}$ & $\begin{array}{c}\text { Iny }_{\mathrm{t}} \\
\text { Equation } 2 \\
\text { (restricted) }\end{array}$ & $\begin{array}{c}\text { Iny } \\
\text { Equation } 2 \\
\text { (old GDP) }\end{array}$ & $\begin{array}{c}\text { Iny }_{t} \\
\text { Equation } 3 \\
\text { (restricted) }\end{array}$ \\
\hline $\mathrm{InH}_{\mathrm{t}-1}$ & $\begin{array}{c}0.600 \\
\left(2.340^{\star}\right)\end{array}$ & & & & \\
\hline $\operatorname{lnK}_{t-1}$ & $\begin{array}{c}0.449 \\
\left(6.626^{\star \star}\right)\end{array}$ & & & & \\
\hline $\operatorname{lnk}_{t-1}$ & & $\begin{array}{c}0.454 \\
\left(7.223^{\star \star}\right)\end{array}$ & $\begin{array}{c}0.431 \\
\left(7.289^{\star *}\right)\end{array}$ & $\begin{array}{c}0.413 \\
\left(6.995^{\star *}\right)\end{array}$ & $\begin{array}{c}0.385 \\
\left(5.760^{\star \star}\right)\end{array}$ \\
\hline $\operatorname{lnH}_{\mathrm{at}(-1)}$ & $\begin{array}{l}-0.212 \\
(-0.454)\end{array}$ & $\begin{array}{l}-0.103 \\
(-0.886)\end{array}$ & & & \\
\hline EV & & & & & $\begin{array}{c}0.559 \\
\left(2.987^{\star *}\right)\end{array}$ \\
\hline NSE & $\begin{array}{c}0.334 \\
\left(2.452^{\star}\right)\end{array}$ & $\begin{array}{c}0.318 \\
\left(2.369^{\star}\right)\end{array}$ & $\begin{array}{c}0.258 \\
\left(1.844^{\prime}\right)\end{array}$ & $\begin{array}{c}0.251 \\
\left(1.816^{\prime}\right)\end{array}$ & $\begin{array}{c}0.309 \\
\left(1.741^{\prime}\right)\end{array}$ \\
\hline Ud & $\begin{array}{c}8.555 \\
\left(4.893^{\star \star}\right)\end{array}$ & $\begin{array}{c}8.405 \\
\left(4.936^{\star \star}\right)\end{array}$ & $\begin{array}{c}7.663 \\
\left(4.628^{\star \star}\right)\end{array}$ & $\begin{array}{r}7.792 \\
(4.659\end{array}$ & $\begin{array}{c}7.100 \\
\left(4.629^{\star \star}\right)\end{array}$ \\
\hline TRY & $\begin{array}{c}0.875 \\
\left(2.880^{\star \star}\right)\end{array}$ & $\begin{array}{c}0.880 \\
\left(2.899^{\star \star}\right)\end{array}$ & $\begin{array}{c}0.846 \\
\left(2.753^{* *}\right)\end{array}$ & $\begin{array}{c}0.818 \\
\left(2.841^{\star \star}\right)\end{array}$ & $\begin{array}{c}0.816 \\
\left(2.618^{\star}\right)\end{array}$ \\
\hline GAY & $\begin{array}{l}-5.778 \\
\left(-2.527^{\star}\right)\end{array}$ & $\begin{array}{l}-5.914 \\
\left(-2.676^{\star \star}\right)\end{array}$ & $\begin{array}{c}-5.489 \\
(2.396)\end{array}$ & $\begin{array}{l}-5.213 \\
\left(-2.460^{\star}\right)\end{array}$ & $\begin{array}{c}-8.282 \\
\left(-2.992^{\star \star}\right)\end{array}$ \\
\hline GRY & & & & & $\begin{array}{l}13.242 \\
(1.501)\end{array}$ \\
\hline C & $\begin{array}{l}-2.667 \\
(-1.255)\end{array}$ & $\begin{array}{l}-2.214 \\
\left(-5.629^{\star \star}\right)\end{array}$ & $\begin{array}{l}-2.454 \\
\left(-9.459^{\star \star}\right)\end{array}$ & $\begin{array}{c}-2.536 \\
(-10.071)\end{array}$ & $\begin{array}{c}-2.618 \\
\left(-8.794^{\star \star}\right)\end{array}$ \\
\hline Adj. $R^{2}$ & 0.989 & 0.964 & 0.961 & 0.960 & 0.962 \\
\hline DW (original) & 1.721 & 1.559 & 1.335 & 1.382 & 1.183 \\
\hline $\begin{array}{l}\text { DW } \\
\text { (transformed) }\end{array}$ & 1.876 & 1.843 & 1.776 & 1.767 & 1.469 \\
\hline
\end{tabular}

Note: Figures in parentheses are t-ratios. Those with ' are significant at the 10 per cent level, with * are at the 5 per cent level and with ** are at the 1 per cent level. 
The restricted and unrestricted models obtained significant results and very similar estimates (Equations 1 and $\left.1^{\prime}\right)$. Adjusted $\mathrm{R}^{2} \mathrm{~s}$ are high, and the DurbinWatson statistics are acceptable at the 5 per cent level. Both models indicate a 0.45 elasticity of capital. The unrestricted model shows an increasing returns-toscale character in the economy, with the elasticity of human capital being 0.60 and significant at the 5 per cent level. The restricted model implies a 0.55 elasticity of human capital, but the externality of average human capital stock $\left(\mathrm{H}_{\mathrm{a}}\right)$ in both models becomes negative (but insignificant). Both models show significant positive effects of marketisation (NSE), urbanisation (Ud) and foreign trade (TRY) on economic growth, and both show negative and significant effects of government administration expenses on growth. Omitting $\mathrm{H}_{\mathrm{a}}$ results in only slight changes in estimates. The elasticity of capital becomes 0.43 , and other TFP-related coefficients are slightly lower (Equation 2). Foreign investment (FI) was omitted from Equations 1 and 2 because of its low t-ratios.

The non-positive externality of $\mathrm{H}_{\mathrm{a}}$ is worth further investigation. Some evidence has shown possible misallocation of China's educational resources. These resources might be under-allocated in vocational education and over-allocated in regular secondary education. Most high schools aim to provide only as many candidates as possible for universities with high examination marks. Three-quarters of the junior and senior high school students, however, have to be employed without entering tertiary education, and mostly without any job training. To test the possible different growth effects between vocational and regular education, the author calculated new graduates' years of schooling from secondary vocational schools as a ratio of that from the whole secondary schools, from 1952 to 2005. This new variable (EV) is included in Equation 3 in Table 3.3. Government expenses (GRY) on research and development as a ratio of GDP are also included. EV is significant at the 1 per cent level, implying an additional contribution of vocational education to TFP. The estimate of GRY is also positive, and large, but the t-ratio is below significance level $(\mathrm{t}=1.501)$. These effects are, however, not confirmed because the Durbin-Watson statistics fall into the undetermined interval, although they likely do exist.

Using the estimates and statistical data, the effects of marketisation, urbanisation and economic openness (trade) on TFP growth are derived in Table 3.4. The table shows that the sum of these effects made no positive contribution to TFP growth during the pre-reform periods, but contributed about two percentage points during all the sub-periods of economic reform since 1978. The calculation results in Table 3.4 suggest that trade played a more important role in the latest period (1998-2005), 
Table 3.4 Sources of TFP growth, 1952-2005 (per cent, annual average)

\begin{tabular}{lcccccc}
\hline & Marketisation & Urbanisation & Trade & $\begin{array}{c}\text { Administration } \\
\text { expenses }\end{array}$ & $\begin{array}{c}\text { Sum } \\
\text { (new data) }\end{array}$ & $\begin{array}{c}\text { Sum } \\
\text { (old data) }\end{array}$ \\
$1952-57$ & -0.83 & 0.21 & 0.05 & -0.85 & -1.43 & -1.36 \\
$1958-67$ & -0.90 & -0.68 & -0.29 & 0.60 & -1.27 & -1.28 \\
$1968-77$ & 0.29 & 0.18 & 0.18 & 0.04 & 0.70 & 0.69 \\
$1978-87$ & 0.45 & 0.52 & 1.44 & -0.26 & 2.15 & 2.11 \\
$1988-97$ & 0.73 & 0.49 & 0.73 & 0.59 & 2.53 & 2.46 \\
$1998-2005$ & 0.31 & -0.19 & 3.17 & -1.33 & 1.96 & 1.91 \\
\hline
\end{tabular}

Sources: Calculated from the estimates and statistical data in National Bureau of Statistics of China, 2006a. China Statistical Abstract 2006, China Statistics Press, Beijing. National Bureau of Statistics of China, 2005c. China Statistical Yearbook, China Statistics Press, Beijing. National Bureau of Statistics of China, 2005d. China Compendium Statistics 1949-2004, China Statistics Press, Beijing.

and government administration and operation costs deducted 1.3 percentage points from TFP growth for the same period. This suggests inefficient and inadequate uses of public financial resources, highlighting the importance of reforming public financial systems to make governance more efficient and transparent.

Note that the above results on TFP growth imply a rate higher than the 2 per cent TFP growth that might be derived from a conventional production function method using only capital and labour as inputs. This is because growth of human capital stock is faster than growth of the labour force, resulting from expansion of education scales. In the past 27 years, from 1978 to 2005, average years of schooling of the labour force increased by nearly four years, from 5.3 to 9.2 years per person. Human capital growth rate is higher than the growth rate of the labour force by 2.1 per cent, on average (author's calculation). This is evidence that human capital accumulation, rather than simple expansion of the size of the labour force and reallocation of labour between different sectors, is becoming more and more important for economic growth.

As shown in Table 3.3, estimates based on the unrevised statistical data of GDP are very close to those based on the new data. This induces a similar calculation of the contribution to TFP (see the last column of Table 3.4). However, as shown in the first section of this chapter, the revised GDP growth rate for the period 1992-2004 was only 0.5 percentage points higher than the old one. It could be 1.3 percentage points higher if an alternative (probably more reasonable) deflator is used. This implies that TFP could be close to one percentage point higher than has been estimated here. 


\section{Conclusion}

China is now the fourth largest economy in the world, according to the exchangerate measure of GDP, or the second largest, according to the PPP measures. After the statistical revision, its size is nearly 17 per cent larger than stated earlier. For the period 1992-2004, the economic growth rate was officially revised upwards by 0.5 percentage points, to an average of 9.9 per cent. There are, however, reasons to believe that the real growth rate might be even higher, and has risen further in 2006.

Meanwhile, China is still a poor country in per capita terms, although not as poor as previously thought. In 2005, China's per capita GDP increased to US $\$ 1,700$ (and it is likely to be US\$5,000-6,500 by different PPP measures).

There was understatement as well as overstatement of economic achievement in Chinese statistics. The new economic census revealed that the size of the tertiary industry sector has been seriously under-reported. According to the new statistics, the share of tertiary industries in 2005 was 40.2 per cent, which is closer to the normal range for developing countries than had been indicated by the earlier data.

The data revision did not, however, change the structural abnormality in terms of savings and consumption - that is, very high saving rates and a low proportion of private consumption in total GDP. In 2005, private consumption accounted for only 38.2 per cent of GDP, a 50-year low. This pushed up investment, creating over-capacity in industry and pressure on exports. This indicates a need for sustainable growth in the long run to encourage private consumption by job creation, improving social security systems to cover low-income earners, and improving public services.

Using the revised data, growth accounting in this study found that human capital is now playing an important role in China's economic growth. Further developing the education system-especially improving vocational education-can be an important measure for human capital accumulation, and therefore for sustaining rapid growth in the future.

The study also found at least two percentage points of TFP growth in nearly three decades, a result mainly of marketisation, urbanisation and economic openness. Government spending on research and development probably made a positive contribution to TFP, although this needs further confirmation.

An important finding of this study is the negative and significant impact of government administration and operating costs. To sustain economic growth, reform to improve governance of public financial systems will be essential. 


\title{
Acknowledgments
}

\author{
This chapter was completed during the author's visit at the Asian Development \\ Bank Institute. The author thanks the institute for its support, and Ross Garnaut \\ and Ligang Song at the Australian National University for their valuable comments \\ and encouragement.
}

\section{Notes}

1 Two directions of biases in GDP statistics existed previously. One was that output data at the local level in various localities were seriously, and arbitrarily, over-reported, under the influence of local governments. This problem was reported widely in the media and noticed not only by the National Bureau of Statistics, but by a number of academics, including the author and his colleagues (see, for example, Wang and Meng 2001). This was also the reason why the National Bureau of Statistics made downward adjustments to the raw data when it was calculating GDP at the national level. Another indication of bias was the missing values from tertiary industry due to the incomplete statistics system for that sector. This problem is rarely recognised because it relies on inside knowledge of the methodologies for data collection and calculation. Seemingly, even National Bureau of Statistics staff did not fully recognise this before the economic census.

2 For the default deflator (Deflator 1), the weights are taken as CPI 0.4, PIIP 0.3, PPIF 0.1, FIPI 0.2. For Deflator 2, the four price indexes are weighted equally (each 0.25 ). For Deflator 3 , the weights are CPI 0.6, PIIP 0.2, PPIF 0.1, FIPI 0.1. GDP in constant prices, derived using these three deflators, gives very close results in average growth rates for the period 1992-2005. They are 10.76 per cent, 10.83 per cent and 10.68 per cent, respectively. The reason for giving the $\mathrm{CPI}$ a greater weight in Deflators 1 and 3 is to make up the defect that PIIP and PPIF reflect only price changes in the primary and secondary industries at the producer side, whereas CPI covers price changes in the services sector. An available price index that the author did not use is the Purchasing Price Index for Raw Materials, Fuel and Power. The reason for its exclusion is that its impact is already included in other indexes, and it might result in an over-weighting of these products.

3 Chow (1993) calculated that capital stock in the non-agricultural sectors was 58.3 billion yuan in 1952 (1952 price), of which fixed capital stock was 31.6 billion. He estimated a 45 billion yuan capital stock in the agricultural sector, including non-fixed capital. Based mainly on these calculations, and considering that capital stock might be more or less underestimated due to incomplete data, the author took a total of 69 billion yuan fixed capital stock in 1952 at the 1952 price. In an earlier study, the author estimated a RMB160 billion capital stock in 1952 (Wang 2000), which should include non-fixed capital stock (and might be a bit too large). Therefore, it is inconsistent with later figures sourced from fixed investment. Nevertheless, I should mention that the 1952 capital stock consists only of a very small part of total capital for later periods (less than 10 per cent in 1980, and less than 1 per cent in 2002), therefore its variation does not have a significant impact on the result of growth accounting.

4 This might result in overestimation of the overall human capital stock, because retired person years are not deducted. However, comparing the result with the national census data in several key years, average years of schooling from the former are lower than the latter. This might result from 1) possible overstatement of education levels in the censuses, and 2) underestimating the years of schooling of those quitted. The calculation therefore seems acceptable. 